\title{
Shyness: Subtypes, Psychosocial Correlates, and Treatment Interventions
}

\author{
Katherine M. Jones ${ }^{1}$, Jay Schulkin², Louis A. Schmidt ${ }^{3}$ \\ ${ }^{1}$ Department of Psychology, American University, Washington DC, USA \\ ${ }^{2}$ Department of Neuroscience, Georgetown University, Washington DC, USA \\ ${ }^{3}$ Department of Psychology, Neuroscience \& Behavior, McMaster University, Hamilton, Canada \\ Email: KJones@acog.org
}

Received 28 December 2013; revised 25 January 2014; accepted 16 February 2014

Copyright (C) 2014 by authors and Scientific Research Publishing Inc.

This work is licensed under the Creative Commons Attribution International License (CC BY).

http://creativecommons.org/licenses/by/4.0/

(c) (i) Open Access

\begin{abstract}
Decades of research on the study of introversion and extraversion have allowed researchers to distinguish among individual differences on each of these dimensions. Research indicates that shyness, a rather common personality trait, is a construct that is related, but not identical, to introversion. Once regarded as a unitary construct, modern day personality theorists propose that shyness is based on a number of orthogonal dimensions. Empirical evidence suggests that distinct subtypes of shyness develop as a result of differences in social approach and social avoidance behaviors. Temperamental shyness is a risk factor for behavioral and affective problems, as well as more severe psychological problems. This article focuses on the phenomenon of shyness by reviewing its subtypes, psychosocial correlates, and efficacious treatment interventions.
\end{abstract}

\section{Keywords}

Shyness; Introversion; Subtypes; Psychosocial Correlates; Treatment Interventions; Social Anxiety; Risk Taking; Psychopathology

\section{Introduction}

As research in personality and developmental psychology flourishes, theories regarding human personality continue to evolve. Once classified by Greek philosophers as having discrete types based on the balance of bodily humors, modern day personality theorists conceptualize personality on a continuum, which is based upon a number of orthogonal dimensions, such as extraversion and introversion (Mathewson \& Schmidt, 2009; Thomas \& Chess, 1977; Zuckerman, 1991). Within these two dimensions of personality the breadth of research has greatly expanded. Shyness is a concept that is related, yet not identical, to introversion with an extensive history 
in the field of psychology that dates back to the ideas of Hans Eysenck (1947) (for reviews see Carducci, 1999; Jones, Cheek, \& Briggs, 1986; Lewinsky, 1941; Rubin \& Asendorpf, 1993; Zimbardo, 1977).

Eysenck (1947) believed that most individual differences in personality could be explained by varying and interacting levels of neuroticism and extraversion. The initial concept of shyness was rooted in this interaction. Individuals low on extraversion and high on neuroticism were characterized as being socially shy. A distinction can be made between individuals who are introverted and individuals who are characterized as temperamentally shy. For example, both introverted and shy children may prefer to be alone and engage in solitary play activities; however, an introverted child does not typically display overt signs of anxiety and is unlikely to experience difficulties in social interactions. On the other hand, an extremely shy child is likely to display overt signs of distress and experience problems when attempting to enter social situations (Schmidt \& Fox, 1999).

Attachment theorists argue that children develop an internalized view of the self from the quality of their early experiences with their parents or caregiver(s) (Bowlby, 1973). Most children develop a secure attachment relationship with their parents characterized by trust and warmth. These children feel competent and self-assured and view the world as a safe place to explore. However, some children develop insecure relationship attachments as a result of unresponsive or insensitive parents/caretakers. Children with insecure attachments display feelings of low competence and low self-worth and view the world as an unpredictable, scary place. Children with secure attachments are more likely to interact with others during novel situations, whereas children with insecure attachments are more likely to display patterns of behavioral inhibition in unfamiliar situations. Several empirical studies have demonstrated an interaction between insecure attachment and shyness/behavioral inhibition (e.g., Calkins \& Fox, 1992; Erickson, Sroufe, \& Egeland, 1985; Kochanska, 1995; Nachmias et al., 1996; Spangler \& Schieche, 1998).

Over the last two decades, there has been an increase in the amount of research dedicated to the study of shyness. Shyness is a common and pervasive phenomenon that over $90 \%$ of the general population has reported experiencing at some point in their lives (Zimbardo, 1977). Temperamental shyness is a personality feature that emerges during early infancy and is characterized by a more severe and persistent form of shyness and social withdrawal. Ten to fifteen percent of people experience temperamental shyness (Kagan, 1994).

The purpose of this article is to focus on the phenomenon of shyness. The article is divided among several sections that will address: the definition and conceptualization of shyness; shyness subtypes; psychosocial correlates; and efficacious treatment interventions.

\section{Definition and Conceptualization}

Shyness is defined as an anxious preoccupation of the self in response to real or imagined social interactions (Melchoir \& Cheek, 1990). Shyness is characterized by active avoidance of social contact (Rubin, Stewart, \& Coplan, 1995) due to fear of social scrutiny and embarrassment, feelings of negative self-worth (Crozier, 1981), low self-esteem (Schmidt \& Fox, 1995), anxiety (Hirshfeld et al., 1992), and occasionally depression (Schmidt \& Fox, 1995). Some theorists explain the etiology of shyness from a trait perspective. Trait perspectives assert that shyness functions as a dimension of personality (e.g., Cheek \& Krasnoperova, 1999) and has biological and temperamental origins (Kagan, 1994). Other theorists suggest that shyness emanates from feelings of shame and embarrassment that result in social inhibition (e.g., Crozier, 1999).

There are a range of measurable correlates of shyness that are found in children and adults. These correlates include: psychophysiological (e.g., high morning and daytime cortisol levels, right frontal brain electrical asymmetry, and heightened baseline heart rate; Beaton et al., 2006; Schmidt, 1999; Schmidt, Santesso, Schulkin, \& Segalowitz, 2007); cognitive/affective (e.g., low self-esteem, anxious thoughts, heightened negative emotion; Ashbaugh, Antony, McCabe, Schmidt, \& Swinson, 2005; Brunet \& Schmidt, 2007, 2008; Crozier, 1981); behavioral (e.g., behavioral inhibition, startle response, gaze aversion, reduction in speech; Pilkonis, 1977a,b; Snidman \& Kagan, 1994); and psychosocial (e.g., social anxiety disorder, substance use disorders, eating disorders; Beidel \& Turner, 1998; Zuckerman, 1994; Bulik, Sullivan, Weltzin, \& Kaye, 1995).

Although decades of research have been dedicated to studying human shyness, problems with adequately defining shyness persist. Researchers in the field have used numerous terms interchangeably to characterize and study similar constructs such as social reticence, social isolation, social withdrawal, social anxiety, social phobia, introversion, timidity, low sociability, social inhibition, social wariness, and behavioral inhibition (for reviews see Rubin \& Asendorpf, 1993; Schmidt \& Buss, 2010). These definitions of shyness are used interchangeably to 
characterize both childhood and adult shyness. However, all of these terms have different origins, meanings, correlates, and outcomes. Failure to clearly conceptualize and define the terms that we use to characterize human shyness continues to hinder further scientific study of the phenomenon.

\section{Shyness Subtypes}

Shyness was originally believed to be a unitary construct (Pilkonis, 1977a, b); however, due to disagreement regarding the conceptualization of shyness, some have suggested that the construct of shyness is multidimensional (Crozier, 1981). Different subtypes of shyness have since been proposed. Buss (1986) suggested that there are at least two types of shyness: a fearful shyness and a self-conscious shyness. According to Buss, fearful shyness emerges early in development during ages 6-12 months and is associated with the infant's fear of strangers. Fearful shyness does not require self-awareness and is associated with inhibition in novel situations. Self-conscious shyness is a later-developing subtype of shyness that emerges around 3 to 4 years of age and coincides with the development of self-awareness, perspective taking, embarrassment, and self-conscious emotions. Self-conscious shyness involves an individual's ability to assume a detached-observer perspective toward the self.

Empirical evidence suggests differences between the two shyness subtypes on multiple levels. Bruch, Giordano, and Pearl (1986) reported that the two subtypes differed on self-report measures of behavioral inhibition, social skills, and somatic anxiety. Fearfully shy adults experienced greater difficulties in these areas. Results also indicated that fearful shyness had an earlier onset than self-conscious shyness. Schmidt and Robinson (1992) found that fearfully shy adults had significantly lower self-esteem than self-consciously shy adults.

A more recent conceptual framework of shyness subtypes developed by Asendorpf proposes that shyness and sociability are two independent personality traits, distinguishable across a variety of measures (Asendorpf, 1990, 1993; Asendorpf \& Meier, 1993). Asendorpf (1990) proposed that different types of shyness develop as a result of differences in social approach and social avoidance behaviors. Asendorpf (1990) argued that high and low social approach and social avoidance tendencies yield four possible combinations of social behavior and distinct types of individuals. According to Asendorpf's approach-avoidance heuristic framework, shyness develops from an approach-avoidance conflict (individuals who score high on social approach and social avoidance). Children who are socially shy wish to engage in play activities with their peers but cannot successfully enter the social playgroup. Shy children are contrasted with avoidant children (individuals who score low on social approach and high on social avoidance). Individuals who score low on social approach and low on social avoidance are described as introverts, and those who score high on social approach and low on social avoidance are characterized as sociable. Each of these subtypes of shyness yields different developmental and psychosocial outcomes (Rubin \& Asendorpf, 1993). Shy children experience high levels of anxiety during socially evaluative situations (Fox et al., 1995), whereas children who are described as avoidant are typically socially withdrawn and may experience greater depression (Rubin et al., 1995).

Schmidt (1999) adopted an approach-avoidance paradigm similar to that of Asendorpf (1990). This framework contrasts varying degrees of shyness and sociability. Schmidt described children high in shyness (i.e., "avoidance”) and sociability (i.e., "approach") as conflicted and those high in shyness and low in sociability as avoidant. According to Schmidt's model, children low in shyness and high in sociability are outgoing and sociable, and those low in shyness and sociability are introverted. Avoidant children experience high negative emotion during social interactions (Schmidt \& Fox, 1999). Other studies have found that these children avoid peers, attempt to escape from play interactions, and become emotionally upset during play activities with unfamiliar children (Coplan, Rubin, Fox, Calkins, \& Stewart, 1994). In contrast, conflicted children display difficulty entering into social interactions with peers. They attempt to engage in play activities with peers but are inhibited due to high levels of anxiety. During play situations, conflicted children display overt signs of anxiety, such as increased frequency of self-manipulations and circling the playgroup. Schmidt and Fox (1999) argued that children low in approach and avoidance are mislabeled as another shyness subtype when they are actually displaying the beginning origins of introversion. Introverted individuals prefer to be alone but do not experience the same anxiety that shy individuals do during social interactions.

\section{Psychosocial Correlates of Temperamental Shyness}

Given the theoretical and empirical evidence for the existence of different subtypes of temperamental shyness, it 
is important to consider the psychosocial implications associated with extreme shyness. Psychosocial correlates include behavioral and affective problems, as well as more severe psychological disorders.

\subsection{Behavioral}

Shyness during early infancy and childhood is predictive of adjustment problems later in development (Coplan, Findlay, \& Nelson, 2004). Due to the link between shyness and behavioral inhibition, temperamentally shy infants and children avoid social interactions more than their non-shy counterparts. As a result, shy children may have fewer opportunities to practice and develop social skills, competence, and confidence. Shy individuals also report avoidant and non-constructive coping strategies (Eisenberg et al., 1995), and shy children tend to exhibit low levels of assertiveness (Ollendick, Oswald, \& Francis, 1989). By the time these shy children are schoolaged, they exhibit greater setbacks in these developmental areas (Coplan et al., 2004; McManis, Kagan, Snidman, \& Woodward, 2002; Schmidt et. al, 1999). Due to an increased fear response to novel stimuli exhibited by shy children, they may be less inclined to habituate to unfamiliar stimuli (Schmidt \& Buss, 2010).

\subsection{Affective}

Temperamental shyness has been linked to internalizing negative emotion, low self-esteem, low self-worth, loneliness, distress, negative emotional intensity, dispositional negative affect, depression, and neuroticism (Eisenberg, Fabes, \& Murphy, 1995; Crozier et al., 1999; Schmidit \& Fox, 1995). Some studies have suggested that temperamentally inhibited individuals may be more susceptible to posttraumatic stress disorder following a threatening event (Pynoos et al., 1987; Terr, 1979). Children characterized as conflicted (high social approach, high social avoidance) may develop feelings of low self-esteem and low self-worth after numerous failed attempts to socially engage with peers (Schmidt \& Fox, 1999). Extremely shy children may also develop heightened concern for the self, which can lead to more severe psychological problems like social anxiety (Schmidt, Fox, Schulkin, \& Gold, 1999). Some of these psychological disorders are discussed in the following section.

\subsection{Psychological Disorders}

Social anxiety disorder. Individuals with temperamental shyness show a predisposition to psychopathology (Schmidt \& Fox, 1994). Temperamental shyness is highly linked to the development of social anxiety. Approximately $20 \%$ of healthy infants are born with a temperamental predisposition toward extreme shyness, and roughly one-third of this group experiences severe social anxiety by adolescence (Kagan \& Snidman, 1999). Several other studies have found that children with temperamental shyness are at greater risk for developing social anxiety (e.g., Eisenberg et al., 1998; Hirshfeld et al., 1992).

Individuals with severe and persistent social anxiety may be at higher risk for developing social anxiety disorder (SAD) (Beidel \& Turner, 1998; Hirshfeld et al., 1992; Miskovic \& Schmidt, 2012). SAD is synonymous to social phobia and is the most common anxiety disorder (Bener, Ghuloum, \& Dafeeah, 2011). The 12-month prevalence rate of SAD in the United States is approximately 7\% (Kessler et al., 2005; Kessler, Petukhova, Sampson, Zaslavsky, \& Wittchen, 2012; Ruscio et al., 2008). SAD is marked by persistent anxiety or fear in one or more social contexts in which the individual is exposed to possible scrutiny by others (American Psychiatric Association, 2013). Individuals who do not receive proper psychological treatment for SAD typically experience persistent anxiety coupled with serious social and occupational difficulties (Wong, Sarver, \& Beidel, 2012).

Substance use and risky behavior. Individuals with certain personality types may be more likely to engage in risk-taking and sensation-seeking behaviors, such as substance use (Zuckerman, 1994). Zuckerman (1994) suggested that individuals who engage in frequent sensation-seeking behaviors experience positive arousal from risk-taking. Many studies have demonstrated the link between sensation seeking and illicit drug use (Page, 1990; Zuckerman, 1994; Zuckerman, Neary, \& Brustman, 1970) and alcohol consumption (Johnson, 1989; Lagrange, Jones, Erb, \& Reyes, 1995).

Research suggests an association between shyness (including social anxiety and social phobia) and substance use and abuse. Socially anxious and shy individuals may perceive the use of illicit substances as a coping mechanism to better manage their anxiety and other psychosocial difficulties (Arndt, Tyrell, Flaum, \& Andreasen, 1992). These findings have been noted among both adolescents and adults (Page, 1990; Santesso, Schmidt, \& Fox, 2004). Individuals with SAD often suffer from co-occurring alcohol problems (Mannuzza et al., 1995), and 
self-report measures indicate that they use substances as a coping mechanism to combat feelings of anxiety and fear in social contexts (Smail, Stockwell, Canter, \& Hodgson, 1984). Hartman (1986) found that shy individuals reported using illicit drugs and alcohol to decrease social anxiety compared to non-shy individuals. Hartman (1986) also noted that risk taking was linked to impulsive sensation seeking and sociability.

The Cheek and Buss (Buss, 1986) model of shyness and sociability has been used to further understand the association between temperamental shyness and elevated risk for substance use. Page (1990) examined the link between shyness and sociability and illicit substance use in adolescent males. Page found that shy individuals were more likely to use alcohol and drugs than non-shy individuals. Shy individuals who were highly sociable were also significantly more likely to use hallucinogenic substances than both shy individuals who were less sociable and non-shy individuals.

Schmidt and colleagues (Santesso et al., 2004) used the Cheek and Buss (1986) model of shyness and sociability to assess the associations among shyness, sociability, substance use, and substance use-related behaviors within a sample of American and Canadian participants. Among the American sample, an interaction of shyness and sociability was a significant predictor of substance use and substance use-related behavior more so than either construct alone; these results were not found among the Canadian sample. Results also indicated that individuals who scored high on measures of sensation seeking were more likely to use substances and engage in substance use-related behaviors. These studies suggest that individuals who score high on both shyness and sociability are more likely to engage in risky behaviors, such as substance use.

Eating disorders. Shyness has also been linked to eating pathology in clinical samples (Bulik et al., 1995; Fairburn, Welch, Doll, Davies, \& O’Connor, 1997; Lehoux, Steiger, \& Jabalpurlawa, 2000; Slopien, Rybakowski, \& Rajewski, 2004; Troop \& Bifulco, 2002). Socially conflicted individuals may be at greater risk for developing eating pathology due to increased problems with impulse control, risk taking, and sensation-seeking behaviors (Santesso et al., 2004). Schmidt and colleagues (Santesso et al., 2004) were the first group to investigate the relation between socially conflicted personalities and eating disorders in a non-clinical sample of women. Results indicated that shyness alone reliably predicted eating pathology across a variety of eating problems. However, the interaction between shyness and sociability was not predictive of disordered eating.

\section{Treatment Approaches}

Early identification of temperamental shyness is important for prompt and proper psychological treatment in some severe cases of persistent, extreme shyness and social withdrawal. Parents and teachers should be informed about the early warning signs of shyness to better help identify children with a predisposition to temperamental shyness. Once these children have been identified, there are a number of efficacious treatment options for shyness and SAD. Some of the most widely used treatments are discussed below.

\subsection{Social Skills Training}

Social skills training (SST) is perhaps the most widely used treatment intervention for shyness and social withdrawal. SST is a form of behavior therapy that consists of training in verbal and nonverbal behaviors involved in social interactions. SST incorporates specific techniques, such as modeling, coaching, shaping, role-playing, constructive feedback, and reinforcement of positive interactions. Empirical research indicates inconsistent findings regarding the efficacy of SST (for a review, see Schneider \& Byrne, 1985).

\subsection{Cognitive Behavioral Therapy}

Cognitive behavioral therapy (CBT) and cognitive behavioral group therapy (CBGT) are the most well-researched nonpharmacologic approaches to the treatment of SAD. CBT therapies aim to alter maladaptive thoughts through cognitive restructuring, exposure therapy (imaginal and in vivo exposure), skills training, and relaxation training. In cognitive restructuring, clients challenge and question the validity of their irrational beliefs and are asked to provide evidence against these beliefs (Froján-Parga, Calero-Elvira, \& Montaño-Fidalgo, 2011; Hope et al., 2010). Exposure therapy allows clients to engage in experiments that aim to disprove unrealistic beliefs caused by excessive anxiety (Arch \& Craske, 2008). Numerous studies have demonstrated the efficacy of CBT approaches (individual and group) for the treatment of SAD in children and adults (for reviews, see Bjornsson et al., 2011; Heimberg, 2002; Wersebe, Sijbrand, \& Cuijpen, 2013). 


\subsection{Mindfulness and Acceptance-Based Therapies}

Acceptance and Commitment Therapy (ACT), mindfulness, and mindfulness-based cognitive therapy (MBCT) have also shown to be efficacious treatment approaches in reducing anxiety symptoms and co-occurring depression (Evans et al., 2007; Roemer \& Orsillo, 2002). ACT is a psychological treatment that uses mindfulness, acceptance, and behavioral techniques to facilitate cognitive and behavioral change consistent with individual personal values (Hayes, Villatte, Levin, \& Hildebrandt, 2011). In parallel to CBT relaxation training, ACT (Hayes, Strosahl, \& Wilson, 1999), mindfulness (Kabat-Zinn, 2003), and MBCT (Evans et al., 2007), also emphasize relaxation techniques through breathing and mindfulness exercises and present moment awareness. Several studies have compared the effectiveness of mindfulness and ACT to CBT for the treatment of SAD. Results indicate that mindfulness and acceptance-based therapies are equally effective as CBT in reducing social anxiety in both individual (Kocovski, Fleming, Hawley, Huta, \& Antony, 2013) and group contexts (Arch et al., 2012).

\subsection{The Internet as a Treatment Intervention}

Given that social communication is greatly affected by shyness, the use of the Internet has become a more recent focus for treatment interventions for temperamentally shy individuals. Computers and the Internet provide shy individuals with an alternative mode of communication that may be less anxiety provoking than in-person interactions. Shy individuals may prefer computer-mediated communication (CMC) to face-to-face communication because it offers a chosen degree of identifiability to others, a reduced-cues environment, and a multidimensional platform (e.g., message boards, chat rooms, and newsgroups) to express aspects of one's self (McKenna, Green, \& Gleason, 2002; Sheeks \& Birchmeier, 2007). Sheeks and Birchmeier (2007) found that individuals high in shyness and sociability (i.e., "conflicted”) reported closer and more satisfying online relationships than individuals low in shyness and sociability. These findings suggest that behaviorally inhibited individuals may greatly benefit from CMC with regards to social skills and relationship development.

Titov and colleagues (2008a,b,c; 2010) have dedicated much of their research to studying the use of Internetbased clinician-assisted computerized cognitive behavioral therapy (СаCСBT) and self-guided computerized CBT (CCBT) in their shyness programs. Titov and colleagues argue that CaCCBT and CCBT offer alternative treatment methods that may be more appealing to shy individuals. They also propose that CaCCBT and CCBT address many barriers to treatment seeking among shy individuals, such as stigma associated with treatment seeking and fear and avoidance of negative evaluation during in-person interactions. CaCCBT consists of four components, including 6 online lessons containing education about symptoms and treatment for SAD, CBT homework assignments, an online discussion forum, and regular email contact with a therapist. CCBT is identical to CaCCBT except that it does not involve regular email contact with a therapist or therapist postings in the forum. Studies by Titov and colleagues indicate that CaCCBT and CCBT are efficacious treatments for SAD.

\section{Closing Remarks}

Shyness is a concept that is related, but not identical, to introversion and has a long, rich history in the field of psychology. Decades of research suggest that there are different subtypes of temperamental shyness that emerge from an interaction between social approach and social avoidance behaviors. Each shyness subtype yields a unique personality with differences in behavioral and affective characteristics. Temperamental shyness has various psychosocial correlates that include behavioral and affective problems, as well as more severe psychological disorders. Individuals with extreme shyness are at greater risk for developing SAD, eating disorders, and substance use disorders. Social skills training, CBT therapies, mindfulness and acceptance-based therapies, CMC, CaCCBT, and CCBT have been shown to be efficacious treatment interventions that have long-lasting effects.

Future research should focus on the expansion of treatment options for SAD to real world contexts. Three types of therapies discussed in this article, CBGT, CaCCBT, and CCBT, can be adapted to in-person interactions. Therapists could initially attend CBGT social exposure experiments in real world settings where they could provide peripheral feedback to group members and help them better utilize CBT skills taught in therapy. CaCCBT and CCBT could also add a final component that allows individuals to translate social skills learned and practiced in online settings to in-person interactions. 


\section{References}

American Psychiatric Association (2013). Diagnostic and Statistical Manual of Mentaldisorders (5th ed.). Arlington, VA: American Psychiatric Publishing.

Arch, J. J., \& Craske, M. G. (2008). Acceptance and Commitment Therapy and Cognitive Behavioral Therapy for Anxiety Disorders: Different Treatments, Similar Mechanisms? Clinical Psychology: Science and Practice, 15, 263-279.

Arch, J. J., Eifert, G. H., Davies, C., Plumb, J. C., Rose, R. D., \& Craske, M. G. (2012). Randomized Clinical Trial of Cognitive Behavioral Therapy (CBT) versus Acceptance and Commitment Therapy (ACT) for Mixed Anxiety Disorders. Journal of Consulting and Clinical Psychology, 80, 750-765. http://dx.doi.org/10.1037/a0028310

Arndt, S., Tyrell, G., Flaum, M., \& Andreasen, N. C. (1992). Comorbidity of Substance Abuse in Schizophrenia: The Role of Premorbid Adjustment. Psychological Medicine, 22, 379-388. http://dx.doi.org/10.1017/S0033291700030324

Asendorpf, J. B. (1990). Beyond Social Withdrawal: Shyness, Unsociability, and Peer Avoidance. Human Development, 33, 250-259. http://dx.doi.org/10.1159/000276522

Asendorpf, J. B. (1993). Abnormal Shyness in Children. Journal of Child Psychology and Psychiatry, 34, 1069-1081. http://dx.doi.org/10.1111/j.1469-7610.1993.tb01774.x

Asendorpf, J. B., \& Meier, G. H. (1993). Personality Effects on Children’s Speech in Everyday Life: Sociability-Mediated Exposure and Shyness-Mediated Reactivity to Social Situations. Journal of Personality and Social Psychology, 64, 10721083. http://dx.doi.org/10.1037/0022-3514.64.6.1072

Ashbaugh, A. R., Antony, M. M., McCabe, R. E., Schmidt, L. A., \& Swinson, R. P. (2005). Self-Evaluative Biases in Social Anxiety. Cognitive Therapy and Research, 29, 387-398. http://dx.doi.org/10.1007/s10608-005-2413-9

Beaton, E. A., Schmidt, L. A., Ashbaugh, A. R., Santesso, D. L., Antony, M. M., McCabe, R. E., Schulkin, J. et al. (2006). Low Salivary Cortisol Levels among Socially Anxious Young Adults: Preliminary Evidence from a Selected and a Non-Selected Sample. Personality and Individual Differences, 41, 1217-1228. http://dx.doi.org/10.1016/j.paid.2006.02.020

Beidel, D. C., \& Turner, S. M. (1998). Shy Children, Phobic Adults: Nature and Treatment of Social Phobia. Washington DC: American Psychological Association. http://dx.doi.org/10.1037/10285-000

Bener, A., Ghuloum, S., \& Dafeeah, E. E. (2011). Prevalence of Common Phobias and Their Sociodemographic Correlates in Children and Adolescents in a Traditional Developing Society. African Journal of Psychiatry, 14, 140-145.

http://dx.doi.org/10.4314/ajpsy.v14i2.6

Bjornsson, A. S., Bidwell, L. C., Brosse, A. L., Carey, G., Hauser, M., Mackiewicz Seghete, K. L., Craighead, W. E. et al. (2011). Cognitive-Behavioral Group Therapy versus Group Psychotherapy for Social Anxiety Disorder among College Students: A Randomized Controlled Trial. Depression and Anxiety, 28, 1034-1042. http://dx.doi.org/10.1002/da.20877

Bowlby, J. (1973). Attachment and Loss: Separation, Anxiety, and Anger, vol. 2. New York: Basic Books.

Bruch, M. A., Giordano, S., \& Pearl, L. (1986). Differences between Fearful and Self-Conscious Shy Subtypes in Background and Current Adjustment. Journal of Research in Personality, 20, 172-186. http://dx.doi.org/10.1016/0092-6566(86)90116-9

Brunet, P. M., \& Schmidt, L. A. (2007). Is Shyness Context Specific? Relation between Shyness and Online Self-Disclosure with and without a Live Webcam in Young Adults. Journal of Research in Personality, 41, 938-945. http://dx.doi.org/10.1016/j.jrp.2006.09.001

Brunet, P. M., \& Schmidt, L. A. (2008). Are Shy Adults Really Bolder Online? It Depends on the Context. Cyber Psychology and Behavior, 11, 707-709. http://dx.doi.org/10.1089/cpb.2007.0259

Bulik, C. M., Sullivan, P. F., Weltzin, T. E., \& Kaye, W. H. (1995). Temperament in Eating Disorders. International Journal of Eating Disorders, 17, 251-261. http://dx.doi.org/10.1002/1098-108X(199504)17:3<251::AID-EAT2260170306>3.0.CO;2-V

Buss, A. H. (1986). A theory of shyness. In W. H. Jones, J. M. Cheek, \& S. R. Briggs (Eds.), Shyness: Perspectives on Research and Treatment (pp. 39-46). New York: Plenum Press. http://dx.doi.org/10.1007/978-1-4899-0525-3_4

Calkins, S., \& Fox, N. (1992). The Relations among Infant Temperament, Security of Attachment, and Behavioral Inhibition at Twenty-Four Months. Child Development, 63, 1456-1472. http://dx.doi.org/10.2307/1131568

Carducci, B. J. (1999). Shyness: A Bold New Approach. New York: Harper Collins.

Cheek, J. M., \& Krasnoperova, E. N. (1999). Varieties of Shyness in Adolescence and Adulthood. In L. A. Schmidt, \& J. Schulkin (Eds.), Extreme Fear, Shyness, and Social Phobia: Origins, Biological Mechanisms, and Clinical Outcomes (pp. 224-250). New York: Oxford University Press. http://dx.doi.org/10.1093/acprof:oso/9780195118872.003.0013

Coplan, R. J., Findlay, L. C., \& Nelson, L. J. (2004). Characteristics of Preschoolers with Lower Perceived Competence. Journal of Abnormal Psychology, 32, 399-408. http://dx.doi.org/10.1023/B:JACP.0000030293.81429.49 
Coplan, R. J., Rubin, K. H., Fox, N. A., Calkins, S. D., \& Stewart, S. (1994). Being alone, Playing alone, and Acting alone: Distinguishing among Reticence and Passive and Active Solitude in Young Children. Child Development, 65, 129-137. http://dx.doi.org/10.2307/1131370

Crozier, W. R. (1981). Shyness and Self-Esteem. British Journal of Social Psychology, 20, 220-222. http://dx.doi.org/10.1111/j.2044-8309.1981.tb00537.x

Crozier, W. R. (1999). Individual Differences in Childhood Shyness: Distinguishing Fearful and Self-Conscious Shyness. In L. A. Schmidt, \& J. Schulkin (Eds.), Extreme Fear, Shyness, and Social Phobia: Origins, Biological Mechanisms, and Clinical Outcomes (pp. 14-29). New York: Oxford University Press. http://dx.doi.org/10.1093/acprof:oso/9780195118872.003.0002

Eisenberg, N., Fabes, R. A., \& Murphy, B. C. (1995). Relations of Shyness and Low Sociability to Regulation and Emotionality. Journal of Personality and Social Psychology, 68, 505-517. http://dx.doi.org/10.1037/0022-3514.68.3.505

Eisenberg, N., Shepard, S. A., Fabes, R. A., Murphy, B. C., \& Guthrie, I. K. (1998). Shyness and Children’s Emotionality, Regulation, and Coping: Contemporaneous, Longitudinal, and Across-Context Relations. Child Development, 69, 767790.

Erickson, M. F., Sroufe, L. A., \& Egeland, B. (1985). The Relationship between Quality of Attachment and Behavior Problems in Preschool in a High-Risk Sample. Monographs of the society for research in child development, 147-166. http://dx.doi.org/10.2307/3333831

Evans, S., Ferrando, S., Findler, M., Stowell, C., Smart, C., \& Haglin, D. (2007) Mindfulness-Based Cognitive Therapy for Generalized Anxiety Disorder. Journal of Anxiety Disorders, 22, 716-721. http://dx.doi.org/10.1016/j.janxdis.2007.07.005

Eysenck, H. J. (1947). Dimensions of Personality. London: Methuen.

Fairburn, C. G., Welch, S. L., Doll, H. A., Davies, B. A., \& O’Connor, M. E. (1997). Risk Factors for Bulimia Nervosa: A Community-Based Case Control Study. Archives of General Psychiatry, 54, 509-517. http://dx.doi.org/10.1001/archpsyc.1997.01830180015003

Fox, N. A., Rubin, K. H., Calkins, S. D., Marshall, T. R., Coplan, R. J., Porges, S. W., \& Stewart, S. (1995). Frontal Activation Asymmetry and Social Competence at Four Years of Age. Child Development, 66, 1770-1784. http://dx.doi.org/10.2307/1131909

Froján-Parga, M. X., Calero-Elvira, A., \& Montaño-Fidalgo, M. (2011). Study of the Socratic Method during Cognitive Restructuring. Clinical Psychology \& Psychotherapy, 18, 110-123. http://dx.doi.org/10.1002/cpp.676

Hartman, L. M. (1986). Social Anxiety, Problem Drinking, and Self-Awareness. In L. M. Hartman, \& K. R. Blankstein (Eds.), Psychological Theories of Drinking and Alcoholism (pp. 265-282). New York: Plenum.

Hayes, S. C., Strosahl, K. D., \& Wilson, K. G. (1999). Acceptance and Commitment Therapy: An Experiential Approach to Behavior Change. New York: Guilford Press.

Hayes, S. C., Villatte, M., Levin, M., \& Hildebrandt, M. (2011). Open, Aware, and Active: Contextual Approaches as an Emerging Trend in the Behavioral and Cognitive Therapies. Annual Review of Clinical Psychology, 7, 141-168. http://dx.doi.org/10.1146/annurev-clinpsy-032210-104449

Heimberg, R. G. (2002). Cognitive-Behavioral Therapy for Social Anxiety Disorder: Current Status and Future Directions. Biological Psychiatry, 51, 101-108. http://dx.doi.org/10.1016/S0006-3223(01)01183-0

Hirshfeld, D. R., Rosenbaum, J. F., Biederman, J., Bolduc, E. A., Faraone, S. V., Snidman, N., \& Kagan, J. (1992). Stable Behavioral Inhibition and Its Association with Anxiety Disorder. Journal of the American Academy of Child and Adolescent Psychiatry, 31, 103-111. http://dx.doi.org/10.1097/00004583-199201000-00016

Hope, D. A., Burns, J. A., Hayes, S. A., Herbert, J. D., \& Warner, M. D. (2010). Automatic Thoughts and Cognitive Restructuring in Cognitive Behavioral Group Therapy for Social Anxiety Disorder. Cognitive Therapy and Research, 34, 1-12. http://dx.doi.org/10.1007/s10608-007-9147-9

Johnson, P. B. (1989). Personality Correlates of Heavy and Light Drinking Female College Students. Journal of Alcohol and Drug Education, 34, 33-37.

Jones, W. H., Cheek, J. M., \& Briggs, S. R. (1986). Shyness: Perspectives on Research and Treatment. New York: Plenum Press. http://dx.doi.org/10.1007/978-1-4899-0525-3

Kabat-Zinn, J. (2003). Mindfulness-Based Interventions in Context: Past, Present,and Future. Clinical Psychology: Science and Practice, 10, 144-156.

Kagan, J. (1994). Galen's Prophecy: Temperament in Human Nature. New York: Basic Books.

Kagan, J., \& Snidman, N. (1999). Early Childhood Predictors of Adult Anxiety Disorders. Biological Psychiatry, 46, $1536-1541$. http://dx.doi.org/10.1016/S0006-3223(99)00137-7

Kessler, R. C., Berglund, P., Demler, O., Jin, R., Merikangas, K. R., \& Walters, E. E. (2005). Lifetime Prevalence and Age-of-Onset Distributions of DSM-IV Disorders in the National Comorbidity Survey Replication. JAMA Psychiatry, 62, 
593-602. http://dx.doi.org/10.1001/archpsyc.62.6.593

Kessler, R. C., Petukhova, M., Sampson, N. A., Zaslavsky, A. M., \& Wittchen, H. U. (2012). Twelve-Month and Lifetime Prevalence and Lifetime Morbid Risk of Anxiety and Mood Disorders in the United States. International Journal of Methods in Psychiatric Research, 21, 169-184. http://dx.doi.org/10.1002/mpr.1359

Kochanska, G. (1995). Children’s Temperament, Mothers’ Discipline, and Security of Attachment: Multiple Pathways to Emerging Internalization. Child Development, 66, 597-615. http://dx.doi.org/10.2307/1131937

Kocovski, N. L., Fleming, J. E., Hawley, L. L., Huta, V., \& Antony, M. M. (2013). Mindfulness and Acceptance-Based Group Therapy versus Traditional Cognitive Behavioral Group Therapy for Social Anxiety Disorder: A Randomized Controlled Trial. Behaviour Research and Therapy, 51, 889-898. http://dx.doi.org/10.1016/j.brat.2013.10.007

Lagrange, L., Jones, T. D., Erb, L., \& Reyes, E. (1995). Alcohol Consumption: Biochemical and Personality Correlates in a College Student Population. Addictive Behaviors, 20, 93-103.

Lehoux, P. M., Steiger, H., \& Jabalpurlawa, S. (2000). State/Trait Distinction in Bulimic Syndromes. International Journal of Eating Disorders, 27, 36-42. http://dx.doi.org/10.1002/(SICI)1098-108X(200001)27:1<36::AID-EAT4>3.0.CO;2-U

Lewinsky, H. H. (1941). The Nature of Shyness. British Journal of Psychology, 32, 105-113.

Mannuzza, S., Schneier, F. R., Chapman, T. F., Liebowitz, M. R., Klein, D. F., \& Fyer, A. J. (1995). Generalized Social Phobia: Reliability and Validity. JAMA Psychiatry, 52, 230-237.

http://dx.doi.org/10.1001/archpsyc.1995.03950150062011

Mathewson, K. J., \& Schmidt, L. A. (2009). The Psychology and Physiology of Extraversion. Advances in Psychology Research, 69, 205-215.

McKenna, K. Y. A., Green, A. S., \& Gleason, M. E. J. (2002). Relationship Formation on the Internet: What's the Big Attraction? Journal of Social Issues, 58, 9-31. http://dx.doi.org/10.1111/1540-4560.00246

McManis, M. H., Kagan, J., Snidman, N. C., \& Woodward, S. A. (2002). EEG Asymmetry, Power, and Temperament in Children. Developmental Psychobiology, 41, 169-177. http://dx.doi.org/10.1002/dev.10053

Melchoir, L. A., \& Cheek, J. M. (1990). Shyness and Anxious Self-Preoccupation during a Social Interaction. Journal of Social Behavior and Personality, 5, 117-130.

Miskovic, V., \& Schmidt, L. A. (2012). Social Fearfulness and the Human Brain. Neuroscience and Biobehavioral Reviews, 36, 459-478. http://dx.doi.org/10.1016/j.neubiorev.2011.08.002

Nachmias, M., Gunnar, M., Mangelsdorf, S., Hornik Parritz, R., \& Buss, K. (1996). Behavioural Inhibition and Stress Reactivity: The Moderating Role of Attachment Security. Child Development, 67, 508-522. http://dx.doi.org/10.2307/1131829

Ollendick, T. H., Oswald, D. P., \& Francis, G. (1989). Validity of Teacher Nominations in Identifying Aggressive, Withdrawn, and Popular Children. Journal of Clinical Child Psychology, 18, 221-229.

Page, R. M. (1990). Shyness and Sociability: A Dangerous Combination for Illicit Substance Use in Adolescent Males? Adolescence, 25, 803-806.

Pilkonis, P. A. (1977a). Shyness, Private and Public, and Its Relation to Other Measures of Social Behavior. Journal of Personality, 45, 585-595. http://dx.doi.org/10.1111/j.1467-6494.1977.tb00173.x

Pilkonis, P. A. (1977b). The Behavioral Consequences of Shyness. Journal of Personality, 45, 596-611. http://dx.doi.org/10.1111/j.1467-6494.1977.tb00174.x

Pynoos, R. S., Frederick, C., Neder, K., Arroyo, W., Steinberg, A., Eth, S., \& Fairbanks, L. (1987). Life Threat and PostTraumatic Stress Disorder in School-Age Children. JAMA Psychiatry, 44, 1057-1063.

http://dx.doi.org/10.1001/archpsyc.1987.01800240031005

Roemer, L., \& Orsillo, S. M. (2002). Expanding Our Conceptualization of and Treatment for Generalized Anxiety Disorder: Integrating Mindfulness/Acceptance-Based Approaches with Existing Cognitive-Behavioral Models. Clinical Psychology: Science and Practice, 9, 54-68. http://dx.doi.org/10.1093/clipsy.9.1.54

Rubin, K. H., \& Asendorpf, J. (1993). Social Withdrawal, Inhibition, and Shyness in Childhood. Hillsdale, NJ: Erlbaum.

Rubin, K. H., Stewart, S. L., \& Copland, R. L. (1995). Social Withdrawal in Childhood: Conceptual and Empirical Perspectives. Advances in Clinical Child Psychology, 17, 157-196.

Ruscio, A. M., Brown, T. A., Chiu, W. T., Sareen, J., Stein, M. B., \& Kessler, R. C. (2008). Social Fears and Social Phobia in the USA: Results from the National Comorbidity Survey Replication. Psychological Medicine, 38, 15-28.

http://dx.doi.org/10.1017/S0033291707001699

Santesso, D. L., Schmidt, L. A., \& Fox, N. A. (2004). Are Shyness and Sociability still a Dangerous Combination for Substance Use? Evidence from a US and Canadian Sample. Personality and Individual Differences, 37, 5-17. http://dx.doi.org/10.1016/j.paid.2003.08.023

Schmidt, L. A. (1999). Frontal Brain Electrical Activity in Shyness and Sociability. Psychological Science, 10, 316-320. 
http://dx.doi.org/10.1111/1467-9280.00161

Schmidt, L. A., \& Buss, A. H. (2010). Understanding Shyness: Four Questions and Four Decades of Research. In K. Rubin, \& R. Coplan (Eds.), The Development of Shyness and Social Withdrawal (pp. 23-41). New York: Guilford Press.

Schmidt, L. A., \& Fox, N. A. (1994). Patterns of Cortical Electrophysiology and Autonomic Activity in Adults' Shyness and Sociability. Biological Psychology, 38, 183-198. http://dx.doi.org/10.1016/0301-0511(94)90038-8

Schmidt, L. A., \& Fox, N. A. (1995). Individual Differences in Young Adults' Shyness and Sociability: Personality and Health Correlates. Personality and Individual Differences, 19, 455-462. http://dx.doi.org/10.1016/0191-8869(95)00083-I

Schmidt, L. A., \& Fox, N. A. (1999). Conceptual, Biological, and Behavioral Distinctions among Different Categories of Shy Children. In L. A. Schmidt, \& J. Schulkin (Eds.), Extreme Fear, Shyness, and Social Phobia: Origins, Biological Mechanisms, and Clinical Outcomes (pp. 47-66). New York: Oxford University Press. http://dx.doi.org/10.1093/acprof:oso/9780195118872.003.0004

Schmidt, L. A., Fox, N. A., Schulkin, J., \& Gold, P. W. (1999). Behavioral and Psychophysiological Correlates of Self-Presentation in Temperamentally Shy Children. Developmental Psychobiology, 35, 119-135. http://dx.doi.org/10.1002/(SICI)1098-2302(199909)35:2<119::AID-DEV5>3.0.CO;2-G

Schmidt, L. A., \& Robinson Jr., T. R. (1992). Low Self-Esteem in Differentiating Fearful and Self-Conscious Forms of Shyness. Psychological Reports, 70, 255-257. http://dx.doi.org/10.2466/pr0.1992.70.1.255

Schmidt, L. A., Santesso, D. L., Schulkin, J., \& Segalowitz, S. J. (2007). Shyness Is Necessary but Not Sufficient for High Salivary Cortisol in 10 Year-Old Children. Personality and Individual Differences, 43, 1541-1551. http://dx.doi.org/10.1016/j.paid.2007.04.011

Schneider, B. H., \& Byrne, B. M. (1985). Children’s Social Skills Training: A Meta-Analysis. In Children's Peer Relations: Issues in Assessment and Intervention (pp. 175-192). New York: Springer. http://dx.doi.org/10.1007/978-1-4684-6325-5_11

Sheeks, M. S., \& Birchmeier, Z. P. (2007). Shyness, Sociability, and the Use of Computer-Mediated Communication in Relationship Development. CyberPsychology \& Behavior, 10, 64-70. http://dx.doi.org/10.1089/cpb.2006.9991

Slopien, A., Rybakowski, F., \& Rajewski, A. (2004). Evaluation of Temperament and Personality in Bulimia Nervosa. Psychiatria Polska, 38, 85-93.

Smail, P., Stockwell, T., Canter, S., \& Hodgson, R. (1984). Alcohol Dependence and Phobic Anxiety States. A Prevalence Study. British Journal of Psychiatry, 144, 174-179.

Snidman, N., \& Kagan, J. (1994). The Contribution of Infant Temperamental Differences to Acoustic Startle Response. Psychophysiology, 31, S92.

Spangler, G., \& Schieche, M. (1998). Emotional and Adrenocortical Responses of Infants to the Strange Situation: The Differential Function of Emotional Expression. International Journal of Behavioral Development, 22, 681-706. http://dx.doi.org/10.1080/016502598384126

Terr, L. C. (1979). Children of Chowchilla: A Study of Psychic Trauma. Psychoanalytic Study of the Child, 34, 547-623.

Thomas, A., \& Chess, S. (1977). Temperament and Development. New York: Brunner/Mazel.

Titov, N., Andrews, G., Choi, I., \& Schwencke, G. (2008a). Shyness 2: Treating Social Phobia Online: Replication and Extension. Australian and New Zealand Journal of Psychiatry, 42, 595-605 http://dx.doi.org/10.1080/00048670802119820

Titov, N., Andrews, G., Choi, I., Schwencke, G., \& Mahoney, A. (2008b). Shyness 3: Randomized Controlled Trial of Guided Versus Unguided Internet-Based CBT for Social Phobia. Australian and New Zealand Journal of Psychiatry, 42, 1030-1040. http://dx.doi.org/10.1080/00048670802512107

Titov, N., Andrews, G., Schwencke, G., Drobny, J., \& Einstein, D. (2008c). Shyness 1: DistanceTreatment of Social Phobia over the Internet. Australian and New Zealand Journal of Psychiatry, 42, 585-594. http://dx.doi.org/10.1080/00048670802119762

Titov, N., Andrews, G., Schwencke, G., Robinson, E., Peters, L., \& Spence, J. (2010). Randomized Controlled Trial of Internet Cognitive Behavioural Treatment for Social Phobia with and Without Motivational Enhancement Strategies. Australian and New Zealand Journal of Psychiatry, 44, 938-945. http://dx.doi.org/10.3109/00048674.2010.493859

Troop, N. A., \& Bifulco, A. (2002). Childhood Social Arena and Cognitive Sets in Eating Disorders. British Journal of Clinical Psychology, 41, 205-211. http://dx.doi.org/10.1348/014466502163976

Wersebe, H., Sijbrandij, M., \& Cuijpers, P. (2013). Psychological Group-Treatments of Social Anxiety Disorder: A MetaAnalysis. PLOS ONE, 8, Article ID: e79034. http://dx.doi.org/10.1371/annotation/5f2f7ff4-ecfd-4a41-a162-34c1dd0c962a

Wong, N., Sarver, D. E., \& Beidel, D. C. (2012). Quality of Life Impairments among Adults with Social Phobia: The Impact of Subtype. Journal of Anxiety Disorders, 26, 50-57. http://dx.doi.org/10.1016/j.janxdis.2011.08.012

Zimbardo, P. G. (1977). Shyness: What Is It and What to Do about It. New York: Symphony Press. 
Zuckerman, M. (1991). Psychobiology of Personality. New York: Cambridge University Press.

Zuckerman, M. (1994). Behavioral Expressions and Biosocial Bases of Sensation Seeking. New York: Cambridge University Press.

Zuckerman, M., Neary, R. S., \& Brustman, B. A. (1970). Sensation Seeking-Scale Correlates in Experience and Preferences for Complexity. In Proceedings of the 78th Annual Convention of the American Psychological Association (pp. 317-318). Washington DC: American Psychological Association. 